\title{
PRACTICES OF EDUCATION MANAGERS TO INCREASE TEACHERS' ENTHUSIASM FOR ACHIEVEMENT OF DESIRED RESULTS IN WORK
}

\author{
Abdul Shakoor \\ Sarhad University of Science \& I.T. Peshawar, Pakistan \\ abdulshakoor333@gmail.com \\ Muhammad Javed Iqbal \\ Sarhad University, Islamabad, Pakistan \\ dme@suit.edu.pk
}

\begin{abstract}
The current study explored the practices of educational managers to increase teachers' enthusiasm for the achievement of desired results in work because educational managers and teachers are the important part of educational institutions and without their roles the academic performance cannot be achieved. The present study sought to analyse academic behaviour, personal behaviour, incentives, and contribution of educational managers for the institutional development through teachers' enthusiasm. It was a descriptive and co-relational study and the data were analysed through descriptive statistics, t-test, Pearson correlation, and regression. A questionnaire was used as a tool of the study which was validated by sending to the panel of experts and the reliability of the instrument was tested on Cronbach's alpha and Factor analysis. The population of the study was 279 educational managers and 3617 teachers while the sample of the study was $279(100 \%)$ educational managers and $361(10 \%)$ teachers. The sampling was made on census and simple random sampling. The findings of the study revealed that educational managers' practices towards teachers had weak correlation in motivation, boosting up morale, appreciation, task equal distribution, minimising communication gap, pointing out deficiencies in isolation, respect for teachers, cooperation, realising inner feelings, good conduct of behaviour, creating tension free and relaxed environment, sharing professional knowledge, introducing latest teaching techniques, making teachers energetic and efficient, promoting collegial and cooperative culture, formulating comprehensive school policy, acknowledgement of work contribution, and intervention in the staff duties. It is recommended for the educational managers to promote teachers' enthusiasm for the achievement of the desired result by enhancing motivation, democratic way of dealing, cooperation, and acknowledgement of their work.
\end{abstract}

Keywords: practices; enthusiasm; academic behaviour; personal behaviour; incentives; contribution

\section{Introduction}

Educational managers and the teachers are the key pillars of the educational institutions. There is no institution that could run without the roles of educational managers and teachers. They both have the relationship with one another on daily basis. The school develops when educational managers proceed on the same path toward achieving the same goal and mission but the institution dwindles down when there is no mutual collaboration between both of them.

In educational institutions, educational managers have more responsibilities than the teachers because educational managers are responsible for the whole school indoor and outdoor activities while the teachers are concerned with their subjects and classes and in this way, their vision and approaches are broader than the teachers'.

If we examine the results of the schools, we find a very little number of schools produce outstanding results but the rest of all are showing average or below average results. Now, who is responsible for good and poor results of the schools, either the educational managers or the teachers? To some extent both are responsible but educational managers are more responsible than the teachers and it is the responsibility of the educational managers to engage teachers in their school-based and class-based activities through motivation and encouragement as an enthusiastic tool. Teachers are bound to obey the instructions of the educational managers and the teachers have no right to violate their boss orders.

The purpose of the present study was to analyse the practices of educational managers to increase teachers' enthusiasm for work to achieve the desired results of the educational institutions.

Therefore the objectives of the study were:

1. To explore the academic behaviour of the educational managers;

2. To investigate the personal behaviour of the educational managers;

3. To assess the incentives of the educational managers;

4. To analyse the contribution of the educational managers in promoting teachers' enthusiasm for the achievement of desired results in work 


\section{Review of Literature \\ Enthusiasm}

Enthusiasm is the hidden energy that emerges like a blazing fire and rushes out in the blood to warm up the spirit for making change and bringing successful results in a desired direction as the enthusiastic zeal of educational managers stir the courage of the teachers in desired direction by infusing in them the spirit of emotions and passions in their work (Slechta, n.d.).

\section{Educational Managers}

A number of professional and official assignments are completed by educational managers daily which show their efficiency and visionary approach to deal with the organisations and the performance of the teachers. Duyar and Normore (2012) argue that educational managers provide educational environment to the teachers for increasing their potentialities and stamina of teaching students in terms of their holistic development while Roux (2012) states that educational managers need proper mechanism towards those gaps which are the focal point and concentration of the educational managers for fulfilling the demands of the institutions by the support of teachers.

In this respect, Gul (2005) reveals that educational managers are deficient in exercising motivational skills to build up the teachers' morale for work. He adds that educational managers are weak in team building and human relations skills even as Lee, Walker, and Chui (2012) state that educational managers enhance the learners' performance by boosting up the morale of the teaching staff by direct supervision and appreciation. There are efforts which make their teaching staff active and energetic.

Educational managers develop institutions by their consistent efforts with providing opportunities to teachers regarding their academic strengthening and ensuring their achieved outcomes to develop connection between the assessment practices, instructional approaches, and command in their subjects (UNICEF, 2014) whereas Louis, Leithwood, Wahlstrom, and Anderson (2010) point out that educational managers have to focus on the teachers for achieving goals by fulfilling their professional requirements. Educational managers create a structure to provide opportunities to the teachers for working in groups and making coordination with other teachers.

Educational managers work for the efficiency and performance of teachers. Burdey (2003) views that educational managers take hand in hand with teachers in two ways: distributing workload equally among the staff members and assigning periods to those who would have command over these subjects. Teachers are motivated when they feel that their managers believe in equality and justice. In response, they work for the organisational development with full potential and their zeal for work fulfils the desired targets of educational institutions. On the other hand, Wahyudin (2010) argues that educational managers make efforts to infuse the zeal of enthusiasm in teachers by building up their confidence and in return, they would perform their tasks according to their own thought and vision with full concentration without any feelings of pressure and fear.

Younas (2008) points out that educational managers may play their role in effective communication and reduces communication gap with one another for understanding and removing misconceptions but Shakoor (2018) argues that educational managers have to deal with all the teachers related matters by themselves without informing higher authorities. They may please their staff by assigning them tasks and periods of their choices. It is the task of educational managers to point out and discuss the deficiencies in the performance of teachers in isolation.

Louis and Robinson (2012) have the opinion that educational managers have the responsibility to provide tension free and relaxed environment to the teachers because no institution can develop where there are tension and conflicts. Blau and Presser (2013) indicated that educational managers develop educational institutions by sharing their professional knowledge and skills with the teachers for developing organisational structure. Similarly, Hamzah, Yakop, Nordin, and Rahman (2011) elaborate that educational managers contribute professional knowledge and experience to the teachers for the management of the classrooms and teaching-learning methodologies.

Othman and Abd Rauf (2009) suggest that educational managers may provide awards and rewards to the successful teachers and select their name on a priority basis for the best teacher award. The Engaging School [TES], (2012) indicates that influential educational managers observe the subject command of teachers and in case of any deficiency, assist them by feedback in a positive way and make cooperative behaviour with them. In this regard, teachers' respect in front of the students is essential.

Louis, Leithwood, Wahlstrom, and Anderson (2010) view that educational managers keep into practice instructional techniques and the latest teaching methods that develop teachers academically. By this attempt, target oriented goals may be achieved in a well-organised form with the quality. Murphy (2013) identifies 
that quality improvement of teachers need promoting collegial and corporate culture, ensuring mutual understanding, and formulating comprehensive school policies that give value to the teachers because of developing their confidence level and they know how to proceed and manage their demanded actions.

In the longer interest of organisational development, goal oriented assignments are imperative for the educational managers to exercise their discretion for motivating teachers to execute outstanding performance by eliciting opportunities for their professional growth which is only possible when they have good understanding with their teachers, command on pedagogical skills, and capability to impart teaching skills to the teachers for their professional development (Mulford, 2003) whereas Nelly, Johnson, Pascal, and Andre (2008) view that educational manager may focus on all the pedagogical approaches of the teachers. It is a fact that every teacher has her/his own skills which she/he utilises for her/his students' development. There are teachers in schools who have no experience of teaching. So, the educational managers may counsel teachers politely and provide proper guidelines for upgrading classroom performance.

Rice (2010) recommends that educational managers motivate teachers for achieving expected targets because they have the key role in organisational development. Othman and Abd Rauf (2009) identify that educational managers for the improvement of teachers' performance, modify their tasks which they might achieve and encourage them to make ready their pupils for competitions, and in the response, managers provide awards to the successful teachers on their achievement in goals in desired results.

Educational managers play a discretionary role in promoting change in their schools. According to Salisbury and McGregor (2005), educational managers ensure to facilitate teachers by providing them such an environment where pedagogical skills, teaching competencies, professional learning, and other developments are made to make teachers active and energetic.

Educational managers realise the vision for their institutional development and their deep insight judges what to do and what not to do on the desired occasion. Vision leads managers towards the activities of the teachers in the classroom environment to observe the subject command of the teachers and other activities and if they find any dearth in their staff teaching, then provide feedback and discuss in isolation where no one listens and the teacher would not feel his/her disrespect (The Engaging School [TES], 2012).

Huma (2005) does not compromise on the sub-standard performance of teachers but advices the educational managers to concentrate on inside the classroom environment and teachers' role while they are engaged in the teaching-learning process. She emphasises that it is the duty of educational managers to bring into notice teachers' teaching methods and techniques. Harvey and Holland (2012) state that educational managers form a vision for the academic success by the support of teachers in the environment and they supervise teaching-learning process under their own command and control.

Educational managers have the responsibility to deal with the organisational matters and give special emphasis to teachers and their role in the organisation. They have the liability to deal with the teachers at optimum level and concentrate on their decisions which they take for the development of their teachers. Ugwulashi and Archibong (2012) have commented that in most of the cases, educational managers are responsible because they do not encourage their staff for work and have no strong relationship with them and due to that sheer misunderstanding devastate the educational institutions' environment. Apart from the teachers' performance, the following factors are also involved like poor communication, irregular rules, overcrowded classrooms, ineffective teaching, non-availability of subject teachers, and lack of practice.

\section{Teacher}

A teacher is a person who has the ability to inculcate knowledge among the students through easy means and the students understand what his or her teacher wants (ITSL, 2011). Similarly, Zombwe (2008) (as cited in Senge, 2000, p. 26) defines that a teacher is "...an expert who is capable of imparting knowledge that will help learners to build, identify and to acquire skills that will be used to face the challenges in life. The teacher also provides to the learners' knowledge, skills and values that enhance development".

\section{Method and Procedure}

It was a descriptive and co-relational study and as a tool, the questionnaire based on "Review of Literature" was used. The questionnaire was validated by sending to the panel of experts. They made changes and corrected grammatically and made the language easy for the respondents to understand. Similarly, the research tool reliability was tested on Cronbach's alpha and Factor analysis. In this study Descriptive Statistics, t-test, Pearson Correlation and Regression were applied through SPSS 20.0 software for the tabulation and analyses of data. 


\section{Population and Sample of the Study}

The population of the study was 279 educational managers and 3617 teachers and the sample of the study was $279(100 \%)$ educational managers and $361(10 \%)$ teachers while the rate of return was 192 educational managers and 265 teachers. In this study, the sampling was made on census sampling and simple random sampling. The questionnaire for the educational managers was administered on census sampling because the total population was taken $(100 \%)$ as a sample of the study while the questionnaire for teachers (10\%) was structured on simple random sampling because the sampling was selected from the large population through sample table. In this study, the quantitative sample was made on Krejcie and Morgan (1970) suggested population and sampling table formulation.

Population and Sample

Table 1

\begin{tabular}{|c|c|c|c|c|c|}
\hline & \multirow[b]{2}{*}{ Districts } & \multicolumn{2}{|c|}{ Educational Managers } & \multicolumn{2}{|l|}{$\underline{\text { Teachers }}$} \\
\hline & & Population & $\begin{array}{l}\text { Sample } \\
(100 \%)\end{array}$ & Population & $\begin{array}{l}\text { Sample } \\
(10 \%)\end{array}$ \\
\hline \multirow{3}{*}{ 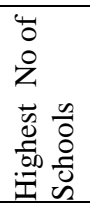 } & Mansehra & 78 & 78 & 1022 & 102 \\
\hline & Peshawar & 77 & 77 & 994 & 99 \\
\hline & Swabi & 75 & 75 & 1180 & 118 \\
\hline \multirow{4}{*}{ 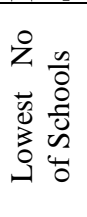 } & Hangu & 23 & 23 & 241 & 24 \\
\hline & Kohistan & 23 & 23 & 158 & 16 \\
\hline & Torghar & 03 & 03 & 22 & 02 \\
\hline & Total & 279 & 279 & 3617 & 361 \\
\hline
\end{tabular}

Source: Annual Statistical Report. District EMIS 2011-12; Govt. of Khyber Pakhtunkhwa, Pakistan

\section{Results}

In this section, the data were tabulated and analysed on $t$-test which is given as under:

Academic Behaviour (AB)

Table 2

\begin{tabular}{lllllll}
\hline No & Statement & $\underline{\text { Mean }}$ & $\underline{\text { St. dev }}$ & $\underline{\mathbf{t}}$ & $\underline{\text { MD }}$ & $\underline{\text { Sig }}$ \\
\hline 1 & Exercising motivational skills & 2.82 & 1.326 & -2.271 & -.185 & .024 \\
2 & Boosting up morale & 2.51 & 1.194 & -6.690 & -.491 & .000 \\
3 & Appreciation & 2.83 & 1.413 & -1.956 & -.170 & .052 \\
4 & Tasks equal distribution & 2.59 & 1.311 & -5.059 & -.408 & .000 \\
5 & Taking staff into confidence & 2.21 & 1.174 & -10.931 & -.789 & .000 \\
6 & Minimising communication gap & 2.42 & 1.226 & -7.719 & -.581 & .000 \\
7 & Pointing out deficiencies in isolation & 2.43 & 1.232 & -7.527 & -.570 & .000 \\
8 & Feedback in a positive way & 2.91 & 1.343 & -.968 & -.094 & .335 \\
\hline & $\alpha=0.05$ & & & & & $\mathrm{n}=457$
\end{tabular}

Table 2 reflects that the mean difference of all the statements is significant except Statement No 3 and 8 . The mean scores and t-values of statement No 1, 2, 3, 4, 5, 6, 7, and 8 are rejected at 0.05 level of significance i.e. "exercising motivational skills", "boosting up morale", "appreciation", "tasks equal distribution", "taking staff into confidence", "minimising communication gap", "pointing out deficiencies in isolation", "observing inside the classroom environment" and "feedback in a positive way".

Table 3

Personal Behaviour (PB)

\begin{tabular}{llllccc}
\hline No & Statement & $\underline{\text { Mean }}$ & $\underline{\underline{\text { St. dev }}}$ & $\underline{\mathbf{t}}$ & $\underline{\text { MD }}$ & $\underline{\text { Sig }}$ \\
\hline 9 & Respectful & 2.72 & 1.26 & -3.607 & -.279 & .000 \\
10 & Making Cooperation & 2.67 & 1.32 & -3.500 & -.333 & .001 \\
11 & Realising inner feelings & 2.67 & 1.32 & -3.500 & -.333 & .001 \\
12 & Good conduct of behaviour & 2.82 & 1.248 & -2.362 & -.181 & .019 \\
\hline \multicolumn{2}{c}{$\alpha=0.05$} & & & & $\mathrm{n}=457$
\end{tabular}

Table 3 shows that the mean difference of all the statements is significant. The mean scores and $t$-values of statement No 9, 10, 11, and 12 are rejected at 0.05 level of significance i.e. "respectful", "making cooperation", "realising inner feelings", and "good conduct of behaviour". 
Table 4

Incentives (IB)

\begin{tabular}{lllllll}
\hline No & Statement & $\underline{\text { Mean }}$ & $\underline{\text { St. dev }}$ & $\underline{\mathbf{t}}$ & $\underline{\text { MD }}$ & $\underline{\text { Sig }}$ \\
\hline 13 & Assigning teachers' choice periods & 2.91 & 1.343 & -.968 & -.094 & .335 \\
14 & Tension free and relaxed environment & 2.50 & 1.187 & -6.880 & -.502 & .000 \\
15 & Award and reward system & 2.23 & 1.295 & -8.190 & -.766 & .000 \\
16 & Recommendation for the 'Best Teacher Award' & 3.66 & 1.107 & 15.267 & .947 & .000 \\
\hline \multicolumn{2}{c}{$\alpha=0.05$} & & & & $\mathrm{n}=457$
\end{tabular}

Table 4 demonstrates that the mean difference of all the statements is significant except Statement No 13. The mean score and t-value of statement No 16 is accepted at 0.05 level of significance i.e. "recommendation for the 'Best Teacher Award'" while the mean scores and t-values of Statement 13, 14, and 15 are rejected at 0.05 level of significance i.e. "assigning teachers' choice periods", "tension free and relaxed environment", and "award and reward system".

Table 5

Contribution (CB)

\begin{tabular}{llccccc}
\hline No & Statement & $\underline{\text { Mean }}$ & $\underline{\underline{\text { St. }}}$ & $\underline{\mathbf{t}}$ & $\underline{\text { MD }}$ & $\underline{\text { Sig }}$ \\
\hline 17 & Sharing professional knowledge & 2.43 & 1.336 & -5.941 & -.573 & .000 \\
18 & Introducing latest teaching techniques & 2.23 & 1.295 & -8.190 & -.766 & .000 \\
19 & Making staff energetic and efficient & 2.55 & 1.224 & -5.972 & -.449 & .000 \\
20 & Promoting collegial and cooperative culture & 2.83 & 1.413 & -1.956 & -.170 & .052 \\
21 & Formulating comprehensive school policy & 2.59 & 1.311 & -5.059 & -.408 & .000 \\
22 & Acknowledgement of work contribution & 2.21 & 1.174 & -10.931 & -.789 & .000 \\
23 & Ensuring mutual understanding & 2.42 & 1.226 & -7.719 & -.581 & .000 \\
24 & Intervention in the staff duties & 2.91 & 1.343 & -.968 & -.094 & .335 \\
\hline & $\alpha=0.05$ & & & & $\mathrm{n}=457$ &
\end{tabular}

Table 5 indicates that the mean difference of all the statements is significant except Statement No 20 and 24. The mean scores and t-values of statement No 17, 18, 19, 20, 21, 22, 23, and 24 are rejected at 0.05 level of significance i.e. "sharing professional knowledge", "introducing latest teaching techniques", "making staff energetic and efficient", "promoting collegial and cooperative culture", "formulating comprehensive school policy", "acknowledgement of work contribution", "ensuring mutual understanding", and "intervention in the staff duties".

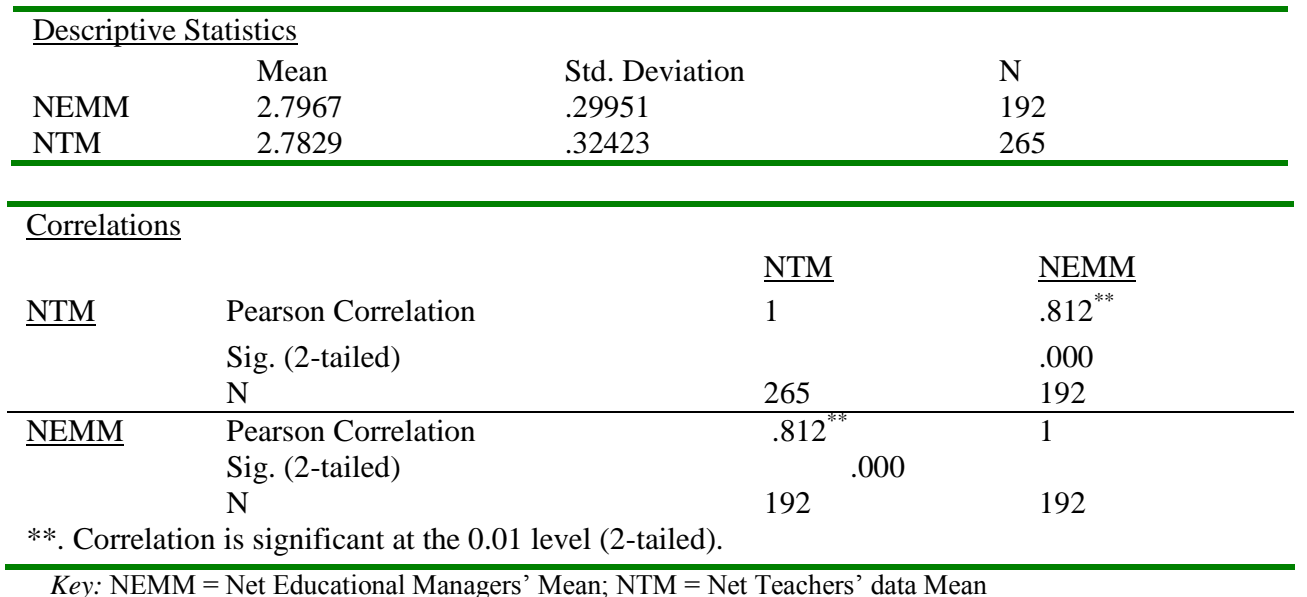

\section{Result Interpretation}

For tables in which both rows and columns contain ordered values, Correlations yield Spearman's correlation coefficient, rho (numeric data only). Spearman's rho is a measure of association between rank orders. Table variables (factors) are quantitative, Correlations yield the Pearson correlation coefficient, the linear association between the variables is significant at $\mathrm{P}>.05$ which shows that there is a relationship between Net Educational Managers Mean (NEMM) and Net Teachers Mean (NTM).

\section{Applying Regression test to evaluate the results}

As explained in methodology, it has assumed that there was no correlation between practices of educational managers $(\mathrm{NEMM}=.812)$ and the teachers' enthusiasm (1) in work for the achievement of the desired result at $(\mathrm{P}=.000)$ significance level. Hence, to capture the effect of independent variable Net 
(NEMM) and dependent variable student's achievement (SA), it has estimated that the regression and results are provided as follows.

(Where SA is representing the dependent variable Students Achievement and NEMM represents predictor variable.

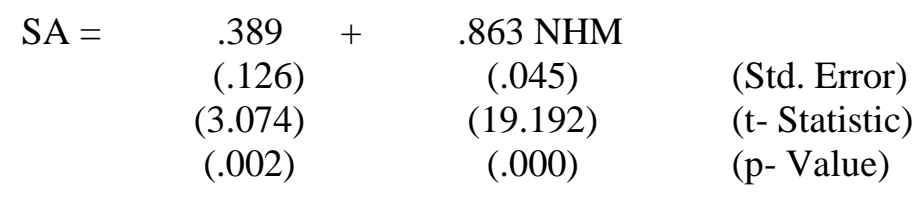

$$
\mathrm{F}=368.315 \quad(\mathrm{p}=000) \quad \mathrm{R}^{2}=.660 \quad \mathrm{R}_{\text {Adj }}^{2}=.658 \quad \mathrm{DW}=1.076 \quad \mathrm{~N}=457
$$

The above-estimated Model is statistically significant as $F=368.315$ at $p<0.05$. A total of 66.00 per cent variation has been explained in dependent variable by variation in explanatory variable NHM. Explanatory variable NHM of student is statistically significant at $\mathrm{p}<0.05$.

The independent variable contributed statistically significantly in a positive way towards student achievement.

\section{Discussion}

The results of the study inferred that there was a weak correlation between practices of educational managers and the enthusiasm in teachers to achieve desired outcomes for the institutional development but the respondents such as educational managers and the teachers had approximately similar views regarding practices of educational managers to increase teachers' enthusiasm for the achievement of desired results in work. Gul (2005) reveals that educational managers are deficient in exercising motivational skills to build up the teachers' morale for work but the study revealed that educational managers were feeble in exercising motivational skills to build up the teachers' moral $(\mathrm{M}=2.82, \mathrm{t}=-2.271)$.

Louis, Leithwood, Wahlstrom, and Anderson (2010) view that educational managers keep into practice latest instructional techniques and methods but the present study found that educational managers did not equip teachers with the latest instructional techniques $(\mathrm{M}=2.23, \mathrm{t}=-8.195)$. So that was the reason that educational institutions did not provide quality results except a few schools but the rest of all had produced average or below average results similarly, on the other hand, Lee, Walker, and Chui (2012) concluded that educational managers enhance the learners' performance by boosting up their morale and appreciation while the study inferred that the majority of educational managers in Khyber Pakhtunkhwa, Pakistan neither boosted up the teachers' morale $(\mathrm{M}=2.51, \mathrm{t}=-6.690)$ and nor did they appreciate $(\mathrm{M}=2.83, \mathrm{t}=-1.956)$ their services and this behaviour of educational managers discouraged the teachers and in reaction, efficient teachers had left their work enthusiastically with emotional spirit.

Burdey (2003) views that educational managers distribute workload equally among the staff members but on the other hand educational managers did not distribute workload equally among the staff members $(\mathrm{M}=2.59, \mathrm{t}=-5.059)$ due to following favouritism policy. The managers assigned to their favourite teachers 15 to 18 periods while those who were not in their good books were assigned 26 to 32 periods.

Wahyudin (2010) argues that educational managers make efforts to infuse the zeal of enthusiasm in teachers by building up their confidence but on actual grounds they did not do it $(\mathrm{M}=2.21, \mathrm{t}=-10.931)$.

Younas (2008) points out that educational managers may play their role in effective communication and minimise communication gap with one another for understanding and removing misconceptions but the study disclosed that educational managers and teachers had no communication with one another due to educational managers authoritative behaviour who considered themselves all in all and avoided to communicate with the teachers and the gap raised misconceptions and clashes in the institute $(\mathrm{M}=2.42, \mathrm{t}=-7.719)$.

Shakoor (2018) indicates that educational managers have to deal with all the teachers' related matters by themselves without informing higher authorities. They may please the staff by assigning to them their choice tasks and periods and point out and discuss their deficiencies in isolation but the present study exposed that majority of educational managers addressed teachers' related matters with high officials and reported to the high ups in writing and did not deal with these matters by themselves $(\mathrm{M}=2.43, \mathrm{t}=-7.527)$. They were undemocratic and assigned periods to the teachers by force instead of by choice either they could teach or not $(\mathrm{M}=2.91, \mathrm{t}=-.968)$. They disrespect teachers in front of the students $(\mathrm{M}=2.72, \mathrm{t}=-3.607)$ and not discussed with them their deficiencies in isolation $(\mathrm{M}=2.91, \mathrm{t}=-.968)$.

The Engaging School [TES] (2012) indicates that educational managers assist the teachers by feedback in a positive way, make cooperation, and respect of them in front of the students but actually the educational managers to some extent provided the feedback in a positive way $(\mathrm{M}=2.91, \mathrm{t}=-.968)$ but they were uncooperative with teachers $(\mathrm{M}=2.67, \mathrm{t}=-3.500)$ and they did not care for the teachers' respect in front of the 
students $(M=2.72, t=-3.607)$. On account of these reasons, teachers were not enthusiastic in their teachinglearning approach. They just wasted the time and the precious time of the students was wasted.

Othman and Abd Rauf (2009) suggest that educational managers may provide awards and rewards to the successful teachers and select their name on priority basis for the 'best teacher award' while the present study revealed that educational managers did not encourage their teachers by providing to them awards and rewards $(\mathrm{M}=2.23, \mathrm{t}=-8.190)$ but selected their names for the 'best teacher award' $(\mathrm{M}=3.66, \mathrm{t}=15.267)$. In this respect, only the names close to the educational managers were selected, but in rear cases, 'best teachers awards' were offered to the original nominees.

Louis and Robinson (2012) have the opinion that educational managers have the responsibility to provide tension free and relaxed environment to their teachers in their institutions but the current study exposed to some extent provide tension free and relaxed environment to their teachers $(\mathrm{M}=2.50, \mathrm{t}=-6.880)$ but in some schools educational managers were the major part of tension and conflicts owing to their behaviour and mismanagement.

Blau and Presser (2013) indicate that educational managers develop educational institutions by sharing professional knowledge with the teachers for the organisational structure but the current study explored that educational managers did not share professional knowledge with their teachers $(\mathrm{M}=2.43, \mathrm{t}=-5.941)$.

Murphy (2013) identifies that quality improvement of teachers need promoting collegial and corporate culture, ensuring mutual understanding, and formulating comprehensive school policies but the study found that educational managers did not have the capability to provide the environment for the promotion of collegial and corporate culture $(\mathrm{M}=2.83, \mathrm{t}=-1.956)$. They did not ensure to produce mutual understanding $(\mathrm{M}=2.42, \mathrm{t}=-7.719)$, and they did not have the plan to formulate comprehensive school policies $(\mathrm{M}=2.59, \mathrm{t}=-$ 5.059) to enlighten their vision in the school environment that how teachers play their role in the school enthusiastically for the desired results of the educational institutions.

\section{Conclusion}

The present study concluded that educational managers' practices for the teachers' enthusiasm through motivation, boosting up morale, appreciation, task equal distribution, minimising communication gap, pointing out deficiencies in isolation, and feedback in a positive way put good impact on the teachers' efficiency and performance because teachers are human beings and it is natural that encouragement makes energetic the subordinates for work with full devotion and emotions. They need little attention and it is sayings, "a soft word turneth away wrath". So, educational managers may avoid negative attitude and thinking among the teachers because of this no institution can develop.

For promoting teachers' enthusiasm in work, they need respect, cooperation, realise inner feelings and good conduct of behaviour because in case of disrespect and uncooperative behaviour, teachers become discouraged and they leave their work. Inner feelings realisation is an art to ponder what the attitude of the subordinates is and why they are behaving this way and in case of not realising or careless attitude, their enthusiastic zeal vanishes away.

Educational managers may assign teachers their choice periods or the periods in which they have command over. They often pressurise their staff members and they create tension and tense environment. They may provide to the staff tension free and relaxed environment and introduce award and reward system and those teachers who are eligible, recommend their names for the best teacher award.

It is in the favour of the institution that educational managers share professional knowledge with their teachers, introduce latest teaching techniques, make staff energetic and efficient, formulate comprehensive school policy, and acknowledgement of the work distribution of the teachers. It puts good effect and in return, teachers try their best to teach more effectively in the class.

Institutions where educational managers and teachers deal with all the matters with mutual understanding, they become successful and institutions ruins who waste the precious time of students. When educational managers deprive teachers by providing incentives to them, the teachers become dishearten and they unwillingly perform their duties.

It is recommended for the educational managers to try to please their teaching staff by any means and in case of their rage and discouragement, only educational managers do not run the school solely. Teachers are the forces who spend throughout the day in taking classes and the educational managers may care for them and appreciate their efforts for producing good results. When teachers are happy, they enthusiastically demonstrate their performance in the class in the form of hard work and it is in the favour of schools that produce desired results with outstanding marks. So, educational managers and teachers may respect each other and mutually perform their tasks for the organisational growth and development. 


\section{Further Researches}

Further study of the issue would be of interest.

5. The study may be conducted to discover the differences in public and private sector practices of educational managers to increase teachers' enthusiasm for the achievement of desired results and also to examine their grounds.

6. This study may be replicated on the educational managers of government girls' high schools and comparison may be made with the boys' high schools.

7. Practices to increase teachers' enthusiasm for the achievement of the desired result in work may be a part of the in-service training of educational managers.

\section{References:}

Blau, I., \& Presser, O. (2013). E-leadership of School Principals: Increasing School Effectiveness by a School Data Management System. British Journal of Educational Technology,44(6), 1000-1011. DOI: 10.1111/bjet.12088.

Burdey, M.B. (2003). Management Issues in Basic Education in Remote Area of Sindh, Pakistan (Unpublished Doctoral Dissertation).University of Karachi, Pakistan.

Duyar, I. \& Normore, A.H. (2012). Discretionary Behavior and Efficiency in Educational Organization: The Missing Link in Educational Leadership and Management. Advances in Educational Administration, 13, xiii-xiv. DOI: 10.1108/S14793660 .

Gul, M. (2005). Assessing The Needs of Educational Administrators at College Level and Development of A Model in Punjab (Unpublished Doctoral dissertation). University of Arid Agriculture, Rawalpindi, Pakistan.

Hamzah, M.I.M., Yakop, F.M., Nordin, N.M., \& Rahman, S. (2011). School as Learning Organization: The Role of Principal's Transformational Leadership in Promoting Teacher Engagement. World Applied Sciences Journal, 14, 58-63.

Harvey, J. \& Holland, H. (2012). The School Principal as Leader: Guiding Schools to Better Teaching and Learning. New York. NY: 10001: The Wallace Foundation. Retrieved January, 15, 2017 from http://www.wallacefoundation.org

Huma, Z. (2005). Analytical Assessment of Management Styles of Principals on Black and Mounton's Gird (Unpublished Doctoral dissertation). University of Arid Agriculture, Rawalpindi, Pakistan.

ITSL (2011). Australian Professional Standards for Teachers. Carlton South, Australia.

Lee, M. Walker, A., \& Chui, Y.L. (April 2012). Contrasting Effects of Instructional Leadership Practices on Student Learning in a High Accountability Context. Journal of Educational Administration, 50(5), 586-611.

Louis, K.S., \& Robinson, V.M. (May 2012). External Mandates and Instructional Leadership: School Leaders as Mediating Agents. Journal Educational Administration, 50(5), 629-665. DOI: 10.1108/09578231211249853.

Louis, K.S., Leithwood, K., Wahlstrom, K.L., \& Anderson, S.E. (2010). Learning from Leadership: Investigating the Links to Improved Student Learning (2010 Annual Report). University of Toronto, Canada: Center for Applied Research and Educational Improvement. Retrieved July, 2010 from www.wallacefoundation.org

Mulford, B. (2003). School Leaders: Challenging Discretionary approaches and Impact on Teacher and School Effectiveness. Paper presented at University of Tasmania, Australia.

Murphy, J. (2013). Legacy Paper: The Architecture of School Improvement. Journal of Educational Administration, 51(3), $252-263$. DOI: $10.1108 / 09578231311311465$.

Othman, R., \& Abd Rauf, F. (2009). Implementing School Efficiency Index (SPIN) in Malaysian Primary Schools. International Journal of Educational Management, 23(6), 505-522. DOI: 10.1108/09513540910981032.

Rice, J.K. (April, 2010). Principal Effectiveness and Leadership in an Era of Accountability: What Research Says, (pp. 1-3) CALDER Working Paper Brief 8. Washington DC: The Urban Institute. Retrieved January, 15, 2017 from http://www.caldercenter.org

Roux, M.J.L. (2012). Principals and Their Possible Power to Influence Quality Education (master's thesis, University of Stellenbosch, South Africa). Retrieved January, 15, 2017 from http://www.scholar.sun.ac.za

Salisbury, C.D. \& McGregor, G. (November, 2005). On Point Series. Principals of Inclusive Schools. Chicago: National Institute for Urban School Improvement.

Shakoor, A. (2018). An Analysis of Discretionary Approaches of High School Heads in Khyber Pakhtunkhwa, Pakistan (Unpublished doctoral dissertation). Sarhad University of Science \& Information Technology, Peshawar, Pakistan.

Senge, J. (2000). Schools that learn. New York, USA: Double day publishing group.

Slechta, R. (n.d.). Leadership Management International, Lake Shore Drive, Waco, USA. Retrieved from: www.lmi-inc.com; info@lmi-inc.com

The Engaging School: A Handbook for School Leaders (May, 2012). London. WC1X9HY: Author.

Ugwulashi, C.S., \& Archibong, F.I. (October, 2012). Human Relations Concept: A Dynamic Approach to Achieving Effective Goals in School Administration. Journal of Educational and Social Research, 2(8), 49-55.

UNICEF (2014). An Introduction to Effective School Principles for Secondary Schools. Eastern Caribbean: Ministries of Education in the Eastern Caribbean Region.

Wahyudin, D. (2010). School Principal as Curriculum Manager: An Approach to the Improvement of Primary School Teachers Performance in Indonesia. Educationist, iv(1), 29-34.

Younas, M. (2008). Work Behaviour of High school Principals (Unpublished master's thesis). Abasyn University, Peshawar, Pakistan.

Zombwe, G. (2008). Who is a Teacher? Quality teachers for Quality education. Tanzania, Dar es Salaam: HakiElimu Position Papers. Retrieved January, 15, 2017 from www.hakielimu.org 